\title{
An Oxygen Vacancy Mediated Ag Reduction and Nucleation Mechanism in $\mathrm{SiO}_{2}$ RRAM Devices
}

\author{
K. Patel ${ }^{1,2}$, J. Cottom ${ }^{1}$, M. Bosman ${ }^{2,3}$, A. J. Kenyon ${ }^{4}$ and A. L. Shluger ${ }^{1}$ \\ ${ }^{1}$ Department of Physics and Astronomy, University College London, Gower Street, London, WC1E 6BT, UK. \\ ${ }^{2}$ Institute of Materials Research and Engineering, A*STAR (Agency for Science, Technology and Research), 2 Fusionopolis \\ Way, Singapore 138634, Singapore. \\ ${ }^{3}$ Department of Materials Science and Engineering, National University of Singapore, Singapore 117575, Singapore \\ ${ }^{4}$ Department of Electronic and Electrical Engineering, University College London, Torrington Place, London, WC1E 7JE, UK.
}

\begin{abstract}
Density Functional Theory (DFT) calculations were used to model the incorporation and diffusion of $\mathrm{Ag}$ in $\mathrm{Ag} / \mathrm{a}_{-} \mathrm{SiO}_{2}$ resistive randomaccess memory (RRAM) devices. The Ag clustering mechanism is vital for understanding device operation, but is poorly understood. In this paper, an $\mathrm{O}$ vacancy $\left(\mathrm{V}_{\mathrm{O}}\right)$ mediated model of the initial stages of Ag clustering is presented, where the $V_{O}$ is identified as the principle site for $\mathrm{Ag}^{+}$reduction. $\mathrm{The}_{\mathrm{Ag}^{+}}$interstitial is energetically favoured at the Fermi energies of $\mathrm{Ag}, \mathrm{W}$ and $\mathrm{Pt}$, indicating that $\mathrm{Ag}^{+}$ions are not reduced at any electrode via electron tunnelling. The adiabatic diffusion barriers of $\mathrm{Ag}^{+}$are lower than $\mathrm{Ag}^{\mathbf{0}}$ with a strong dependence on the local morphology, supporting $\mathrm{Ag}^{+}$being the mobile species during device operation. $\mathrm{Ag}^{+}$ions bind to $\mathrm{V}_{\mathrm{O}}$ forming the $\left[\mathrm{Ag} / \mathrm{V}_{\mathrm{O}}\right]^{+}$ complex, which reduce $\mathrm{Ag}^{+}$via charge transfer from the $\mathrm{Si}$ atoms in the vacancy. The $\left[\mathrm{Ag} / \mathrm{V}_{\mathrm{O}}\right]^{+}$complex is then able to trap an electron forming $\left[\mathrm{Ag} / \mathrm{V}_{\mathrm{o}}\right]^{0}$. The probability for a vacancy to act as a reduction site is 33,33 and $11 \%$ at the $\mathrm{Ag}, \mathrm{W}$ and $\mathrm{Pt}$ electrodes respectively. This complex then acts as a nucleation site for Ag clustering with the formation of $\left[\mathrm{Ag}_{2} / \mathrm{Vo}_{\mathrm{O}}\right]^{+}$which is reduced by the above mechanism.
\end{abstract}

\section{INTRODUCTION}

RRAM devices are typically composed of a metal - insulator metal structure, where the dielectric layer can be switched between high and low states of resistance. During the initial phase of RRAM operation, a conductive filament $(\mathrm{CF})$ is formed across the dielectric layer in a process resembling soft dielectric breakdown. The resistive switching processes involves the breaking and reforming of the conductive filament via application of an electrical field [1]-[7].

The main mechanisms of CF formation and switching are either electrochemical metallisation mechanism (ECM), or valence change mechanism (VCM). In ECM, devices are structured to favour the migration of metal cations into the dielectric layer via field assisted diffusion. The cations are reduced within a- $\mathrm{SiO}_{2}$ at either the active or inert electrode where they nucleate to form metal clusters. This results in a conductive filament of metallic clusters spanning the dielectric giving a low resistance state, where electron transport occurs through the tunnelling of electrons across the metal clusters. The devices can be switched to a high resistance state by the dissolution of metal clusters under a reverse bias. In VCM, defects such as oxygen vacancies or intrinsic charge traps are generated during the forming stage. Electron transport through the dielectric occurs via trap assisted tunnelling through these defect states. Resistive switching occurs by the creation and destruction of these defect states. It has been shown that devices containing a dielectric layer of amorphous $\mathrm{SiO}_{2}\left(\mathrm{a}-\mathrm{SiO}_{2}\right)$ can operate under either of these mechanisms [8], [9]. It is therefore crucial to gain an atomistic understanding of each mechanism and how they compete to better understand how these devices operate and to allow for the subsequent optimisation.

In this study, $\mathrm{Ag} / \mathrm{a}-\mathrm{SiO}_{2} \mathrm{RRAM}$ devices are considered due to the wealth of experimental data allowing for a reliable comparison between theory and experiment [9], [10]. In situ TEM studies of $\mathrm{Ag} / \mathrm{a}-\mathrm{SiO}_{2} / \mathrm{M}(\mathrm{M}=\mathrm{Pt}$ or $\mathrm{W})$ devices show that the clustering mechanism can vary greatly with device structure and microstructure. In the Pt device, multiple Ag filaments grow from the Pt electrode during the forming stage. However, only one filament was found to dominate, spanning $\mathrm{a}-\mathrm{SiO}_{2}$ to form a conductive path between the electrodes. In the case of the $\mathrm{W}$ device, multiple Ag clusters form close to the Ag electrode. Secondary clusters then form in the oxide towards the $\mathrm{W}$ electrode, suggesting the $\mathrm{CF}$ forms iteratively via the building-up of $\mathrm{Ag}$ clusters between the electrodes. The key difference between the devices are the electrode material and the growth method of the oxide layer. An evaporated $\mathrm{a}-\mathrm{SiO}_{2}$ layer in the $\mathrm{W}$ device was used compared to a sputtered a- $\mathrm{SiO}_{2}$ layer in the Pt device. Ag is less mobile in the evaporated a- $\mathrm{SiO}_{2}$ layer compared to the sputtered a-SiO 2 due to a high density of grain boundaries in sputtered films. The formation of multiple Ag clusters in the $\mathrm{W}$ device compared to a single dominating filament in the Pt device suggests a higher concentration of $\mathrm{Ag}$ reduction sites in the $\mathrm{W}$ device compared to a grain boundary related mechanism in the Pt device.

To better understand the mechanisms involved in both devices, calculations will be run with specific attention given to the oxidation and reduction processes. An atomistic understanding of these processes is vital before the nucleation and propagation of the conductive bridge can be described. The $\mathrm{Ag}_{\mathrm{i}}$ and $\mathrm{V}_{\mathrm{O}-\text {-mediated }}$ mechanisms for $\mathrm{Ag}$ reduction and cluster nucleation are investigated in this work.

\section{METHODOLOGY}

In a previous study the $\mathrm{O}$ vacancy was presented as a $\mathrm{Ag}$ reduction site in $\mathrm{a}-\mathrm{SiO}_{2}$ based $\mathrm{RRAM}$ devices using a rings sampling method [11]. To further this work, the mechanism is explored using a complete sampling method where all $\mathrm{O}$ vacancies in a 216-atom a- $\mathrm{SiO}_{2}$ cell are considered. The a- $\mathrm{SiO}_{2}$ cells used in this study are produced using the molecular dynamics melt and quench method implemented in LAMMPS as described in previous studies [12]. DFT calculations were carried out using the Gaussian Plane Wave method (GPW) [13] in the CP2K code[14], [15]. The plane wave cut-off and relative cut-off were set to 600 Ry and 40 Ry respectively with a convergence criteria of $1 \times 10^{-6}$ $\mathrm{eV}$ per formula unit. Double zeta valence polarised (DZVP) 
molecularly optimised (MOLOPT) basis sets [16] and GoedeckerTeter-Hutter (GTH) pseudopotentials [17] were used with the PBE0-TC-LRC functional truncated at $2 \AA$. The auxiliary density matrix method (ADMM) implementation to reduce computational cost [18].

The Ag interstitial was considered in a range of charge states, $-1 \leq \mathrm{q} \leq+2$, providing insights into the charge state dependence on Fermi energy covering the band-gap for a-SiO${ }_{2}$. This was done by the complete spatial sampling of the 216-atom supercell with the density closest to the mean density of 30 structures produced. To do this, a 3-dimensional grid with $2 \AA$ spacing was generated across the supercell giving 512 grid points. From these, grid points were excluded if there was an $\mathrm{a}-\mathrm{SiO}_{2}$ atom less than $1.34 \AA$ away, corresponding to the atomic radius of Ag [19]. The remaining 259 points were used as initial Ag interstitial site locations. In separate simulations, Ag was added at each of the 259 points and the geometry was optimised using the PBE functional for each charge state. From the PBE optimised structures, unique Ag interstitial sites were identified as those having any atom in the cell displaced by more than $0.2 \AA$, an energy difference of greater than $0.1 \mathrm{eV}$, or a Mulliken charge difference of greater than $0.05|e|$. The unique sites were then optimised using the PBE0-TC-LRC functional.

The $\mathrm{O}$ vacancies were sampled by removing each $\mathrm{O}$ in the cell and optimising the geometry using the PBE0-TC-LRC functional in the $-1 \leq \mathrm{q} \leq+1$ charge states. Two sampling methods were tested to study the $\mathrm{Ag} / \mathrm{V}_{\mathrm{O}}$ interaction. The first involved placing $\mathrm{Ag}$ centrally between the two $\mathrm{Si}$ atoms involved in the $\mathrm{O}$ vacancy, and the second involved placing $\mathrm{Ag}$ in a void in proximity to the vacancy. It was found that in all cases where $\mathrm{Ag}$ was placed centrally between the $\mathrm{Si}$ atoms, the $\mathrm{Ag}$ species would relax into a void giving the same, or a lower final energy. As such, this method was selected to reduce the number of calculations required when manually selecting voids in proximity to the vacancy.

The CP2K climbing image - nudged elastic band method (CINEB) was used to model the adiabatic diffusion barriers for $\mathrm{Ag}^{0}$ and $\mathrm{Ag}^{+}$in $\mathrm{a}-\mathrm{SiO}_{2}$. A ring sampling method was selected, where the migration barriers of $\mathrm{Ag}$ and $\mathrm{Ag}^{+}$was calculated through rings of different sizes, $5 \leq \mathrm{N} \leq 8$. In the standard nudged elastic band (NEB) method, the minimum energy path (MEP) is calculated when provided with the initial and final state of the system. A band of 5 replica images is generated through the linear interpolation between the initial and final states in each case. Spring forces, $4.86 \mathrm{eV} \AA^{2}$, connect the replica images to the initial and final states, the geometry of each image is then relaxed to lower the total energy of the band. CI-NEB allows the springs connecting the highest energy images to relax, resulting in a better approximation of the saddle point.

The defect formation energy, Eform, is calculated using the standard formalism of Northrup and Zhang [20]:

$$
E_{\text {form }}=E_{\text {defect }}-E_{\text {pristine }}-\mu_{x}+q\left(\Delta E_{F}+E_{v}\right)+E_{\text {corr }} \text {, }
$$

where $E_{\text {defect }}$ is the total energy of the system with the defect, $E_{\text {pristine }}$ is the total energy of the pristine system, $\mu_{\mathrm{x}}$ is the chemical potential of chemical species, $q$ is the charge of the system, $\Delta E_{F}$ is the Fermi level position, $E_{v}$ is the potential alignment and $E_{c o r r}$ is the charge correction. The Lany-Zunger finite size charge correction scheme was utilised to correct the formation energies of the charges defects, with a dielectric constant of 3.9 and a Madelung constant of 2.8373 for a cubic cell [21].

The chemical potential of $\mathrm{O}, \mu o$, is calculated as one half the energy of an $\mathrm{O}_{2}$ molecule $(\mathrm{S}=1)$. The chemical potential of $\mathrm{Ag}$, $\mu_{A g}$, is calculated from a 162-atom cell of $\mathrm{Ag}_{2} \mathrm{O}$ as:

$$
\mu_{A g}=\frac{1}{2 n}\left(E_{\mathrm{Ag}_{2} \mathrm{O}}-\frac{1}{2} n \mu_{\mathrm{O}_{2}}\right),
$$

where $n$ is the number of $\mathrm{Ag}_{2} \mathrm{O}$ units, $\mathrm{E}_{\mathrm{Ag} 2 \mathrm{O}}$ is the total energy of the $\mathrm{Ag}_{2} \mathrm{O}$ system and $\mu_{\mathrm{O}}$ is the chemical potential of an $\mathrm{O}$ molecule. The chemical potential is taken from $\mathrm{Ag}_{2} \mathrm{O}$ as the $\mathrm{PBE} 0-$ TC-LRC functional poorly describes metals due to the over binding of electron density to nuclei. The Fermi energy positions of $\mathrm{Ag}, \mathrm{W}$ and Pt have been experimentally measured at 4.96, 5.05 and $4.11 \mathrm{eV}$ with respect to the a- $\mathrm{SiO}_{2}$ valence band respectively [22]-[24].

\section{RESULTS AND DISCUSSION}

The initial stages $\mathrm{Ag}$ cluster formation in $\mathrm{Ag} / \mathrm{a}-\mathrm{SiO}_{2} \mathrm{RRAM}$ devices can be separated into several distinct processes. The incorporation of $\mathrm{Ag}$, the ionisation of $\mathrm{Ag}$, the migration of $\mathrm{Ag}$, the reduction of $\mathrm{Ag}$, and finally the clustering of $\mathrm{Ag}$.

\section{A. Ag incorporation in $\mathrm{a}_{-} \mathrm{SiO}_{2}$}

The initial focus is on the incorporation geometries, energies, and charge-state as a function of Fermi energy. This allows the lowest energy charge state of Ag at the Ag, W and Pt electrodes to be determined. Additionally, studying the morphology of the unique interstitial sites provides information about the areas accessible to $\mathrm{Ag}$ in $\mathrm{a}-\mathrm{SiO}_{2}$ during migration.
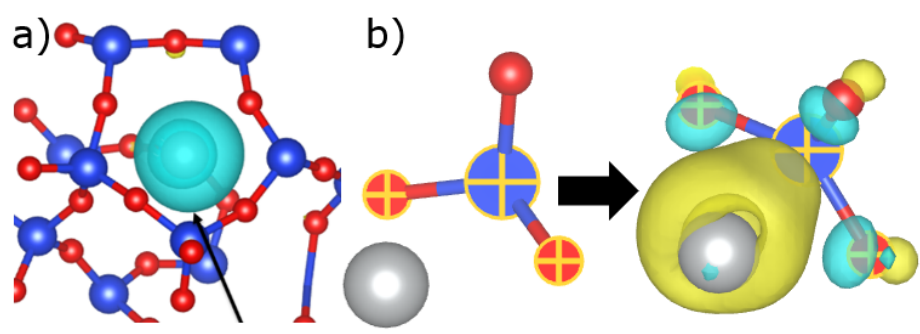

Fig. 1 Schematic showing the HOMO state of two configurations of the $\mathrm{Ag}^{0}$ interstitial in a-SiO 2 . The silver, blue and red spheres correspond to $\mathrm{Ag}, \mathrm{Si}$ and $\mathrm{O}$ atoms respectively. The positive and negative charge density is shown as blue and yellow iso-surfaces, respectively, at a value of \pm 0.07 . a) $\mathrm{Ag}^{0}$ occupies a void in the lattice, with the HOMO state mostly $\mathrm{Ag} s$ in character. b) $\mathrm{Ag}^{0}$ resides near a wide $\mathrm{O}-\mathrm{Si}-\mathrm{O}$ angle bond. $\mathrm{As}^{\mathrm{Ag}}{ }^{0}$ comes into proximity of the O-Si-O angle bond, the O$\mathrm{Si}-\mathrm{O}$ angle increases, with charge donation from $\mathrm{Ag}$ to $\mathrm{Si}$.

From the 259 initial interstitial geometries, 34 and 50 unique sites were found for $\mathrm{Ag}^{0}$ and $\mathrm{Ag}^{+}$, respectively. Analysis of the unique sites for $\mathrm{Ag}^{0}$ show the formation of two types of interstitial defects (Fig.1). The first of these (18 out of 34) involves $\mathrm{Ag}^{0}$ located in a void where the nearest neighbour between $\mathrm{Ag}^{0}$ and the nearest atom in the lattice is between $2.9-3.3 \AA$. The mean Mulliken charge of this defect is $0.02|e|$ showing negligible interaction between $\mathrm{Ag}^{0}$ and the lattice. As shown in Fig. 1a the highest occupied molecular orbital (HOMO) is Ag s-character. 
$\mathrm{Ag}^{0}$ in the second configuration (16 out of 34 ) is closer to the lattice maintaining a nearest neighbour distance of $2.1-2.7 \AA$. In this case, an $\mathrm{O}-\mathrm{Si}-\mathrm{O}$ bond angle widens as seen in Fig. 1b. Charge is then donated from $\mathrm{Ag}^{0}$ to the $\mathrm{Si}$ in the wide angle O-Si-O, Mulliken charge analysis gives a mean $\mathrm{Ag}^{0}$ charge of $0.25|e|$ and a mean charge of $0.19|e|$ donated to $\mathrm{Si}$. From previous studies, it has been seen that sites with $\mathrm{O}-\mathrm{Si}-\mathrm{O}$ bond angles $\geq 130^{\circ}$ can be precursors for electron trapping [12]. The trapping of two electrons at these sites weakens and stretches an O-Si (involved in the $\mathrm{O}-\mathrm{Si}-\mathrm{O})$ bond by $0.5 \AA$ lowering the barriers $(\sim 1 \mathrm{eV})$ for $\mathrm{V}_{\mathrm{O}}$ formation [25]. The spontaneous widening of an O-Si-O bond angle to greater than $130^{\circ}$ was found to occur in 13 of the 34 unique sites.

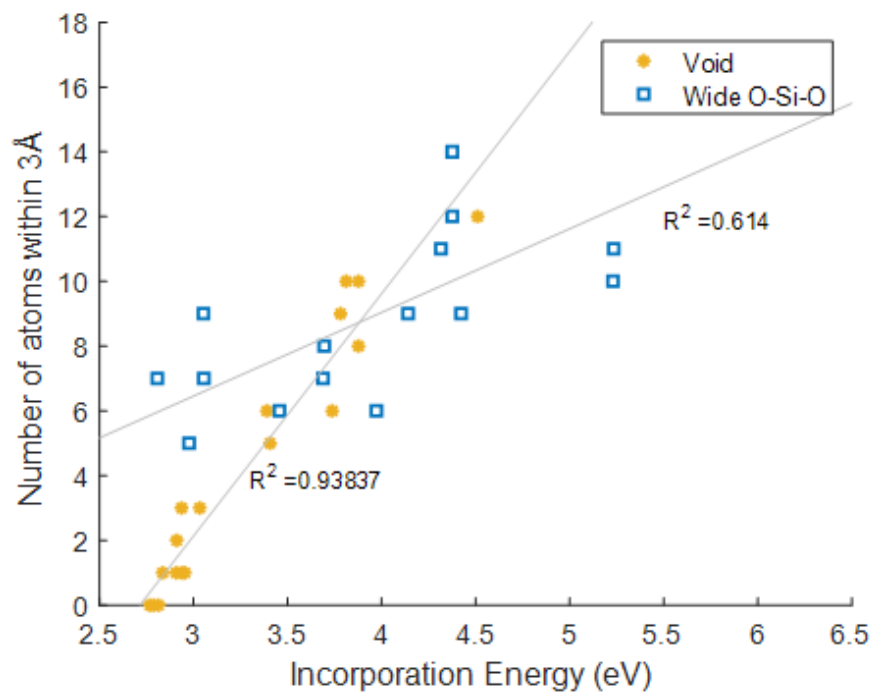

Fig. 2 Graph showing the effect of coordination number to incorporation energy of Ag.

The minimum, and maximum incorporation energies of $\mathrm{Ag}^{0}$ are $2.8 \mathrm{eV}$, and $6.1 \mathrm{eV}$ respectively. There was a strong correlation between the local steric environment and the incorporation energy of $\mathrm{Ag}^{0}$, with the effect being more dominant for void type defects (Fig. 2). The incorporation energy for both types of defect increases with the coordination number, defined as the number of atoms within $3 \AA$ of $\mathrm{Ag}^{0}$, suggesting that $\mathrm{Ag}^{0}$ would reside in the less dense areas of $\mathrm{a}-\mathrm{SiO}_{2} . \mathrm{Ag}^{0}$ atoms interacting with a widened $\mathrm{O}-\mathrm{Si}-\mathrm{O}$ bond angles have lower incorporation energies than void type defects with the same coordination number, suggesting the energetic cost of creating the wide angle $\mathrm{O}-\mathrm{Si}-\mathrm{O}$ is compensated by its interaction with $\mathrm{Ag}$.

$\mathrm{Ag}^{+}$ions were found to favour a weak interaction with a proximate $\mathrm{O}$ in the lattice, where $\mathrm{Ag}^{+}$maintains a nearest neighbour distance between 2.2 - $2.6 \AA$ to a lattice $\mathrm{O}$. The mean Mulliken charge of $\mathrm{Ag}^{+}$is $0.78|e|$, where a strong negative correlation is found between the Mulliken charge and the coordination number. In this case, charge is donated by neighbouring lattice $\mathrm{O}$ to $\mathrm{Ag}^{+}$with the effect more pronounced in dense areas. The geometry of each site shows a preference for $\mathrm{Ag}^{+}$ to be in voids, where ions relax to minimise the distance to nearby $\mathrm{O}$ atoms in the void. As with $\mathrm{Ag}^{0}$, a strong correlation is found between the local steric crowding and the incorporation energy suggesting that both Ag species will propagate though large voids in a-SiO 2 , with higher barriers required to migrate into and through dense areas.

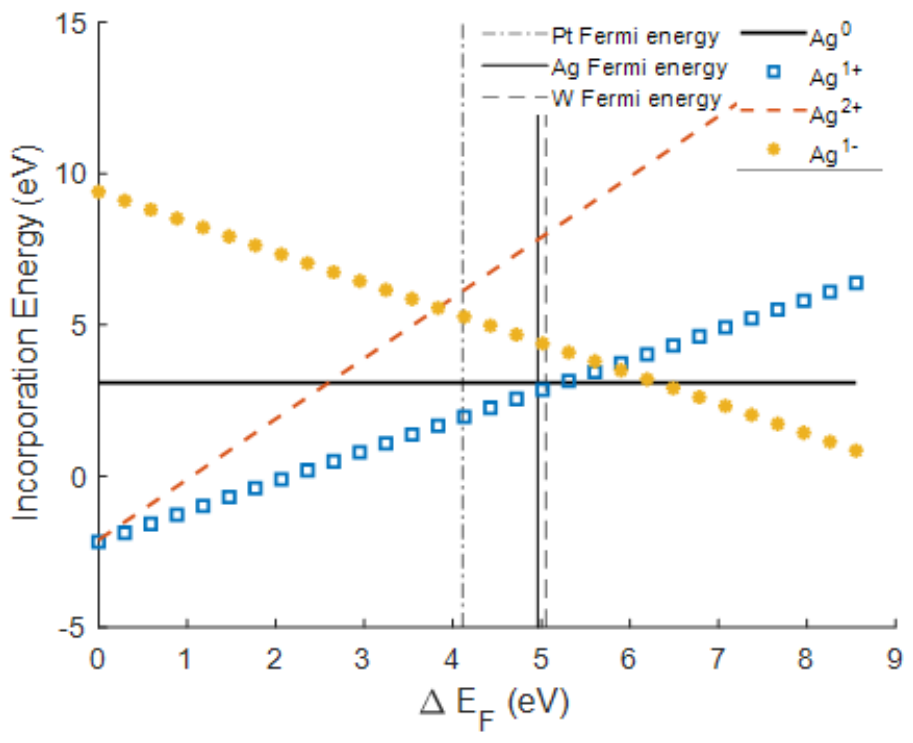

Fig. 3 Incorporation energy diagram of $259 \mathrm{Ag}$ interstitial sites in a-SiO2

The incorporation energy of $\mathrm{Ag}$ in $\mathrm{a}-\mathrm{SiO}_{2}$ can be seen in Fig. 3. The $\mathrm{Ag}^{+}$ion is found to be the most stable charge state with an incorporation energy of $-2.1 \mathrm{eV}$ for an electron chemical potential at the a- $\mathrm{SiO}_{2}$ valence band maximum. $\mathrm{The}^{+} \mathrm{Ag}^{+}$ion is the lowest energy charge state at the Fermi energy of $\mathrm{Ag}, \mathrm{W}$ and $\mathrm{Pt}$ with the mean $(+1 / 0)$ transition at $5.25 \mathrm{eV}$. The $\mathrm{Ag}^{+}$ion is $0.3 \mathrm{eV}$ lower in energy than $\mathrm{Ag}^{0}$ at the $\mathrm{Ag}$ electrode, suggesting that either $\mathrm{Ag}$ is incorporated as an $\mathrm{Ag}^{+}$, or that once $\mathrm{Ag}^{0}$ is incorporated an electron will tunnel from $\mathrm{Ag}^{0}$ to the $\mathrm{Ag}$ electrode forming $\mathrm{Ag}^{+}$ under equilibrium.

Under bias however, the proximity of the Ag electrode Fermi energy to the $(+1 / 0)$ transition adds uncertainty to the lowest energy Ag species. Devices typically operate with positive forming and switching voltages (ranging up to $10 \mathrm{~V}$ and $5 \mathrm{~V}$, respectively) applied to the Ag electrode. Under a positive bias, the Fermi energy position of the Ag electrode would likely shift towards the $\mathrm{a}-\mathrm{SiO}_{2}$ conduction band and enter a regime where $\mathrm{Ag}^{0}$ would be favoured over $\mathrm{Ag}^{+}$. As such the interaction of $\mathrm{Ag}$ with some as yet unidentified defect in $\mathrm{a}-\mathrm{SiO}_{2}$ must be considered in the mechanism for ion generation. The incorporation energy of $\mathrm{Ag}^{+}$ion is $1.1 \mathrm{eV}$ lower in energy than $\mathrm{Ag}^{0}$ at the Pt Fermi energy. The $\mathrm{Pt}$ electrode is grounded during device operation providing strong evidence that a $\mathrm{Ag}$ interstitial in proximity to the $\mathrm{Pt}$ electrode will be an ion. As such, some defect associated mechanism is required for $\mathrm{Ag}^{+}$reduction.

\section{B. Ag diffusion in $\mathrm{a}_{-} \mathrm{SiO}_{2}$}




\begin{tabular}{|c|c|c|c|c|}
\hline $\begin{array}{c}\text { Ring } \\
\text { Size }\end{array}$ & $\begin{array}{c}\mathrm{Ag}^{0} \text { Forward } \\
\text { Barrier (eV) }\end{array}$ & $\begin{array}{c}\mathrm{Ag}^{0} \text { Reverse } \\
\text { Barrier (eV) }\end{array}$ & $\begin{array}{c}\mathrm{Ag}^{+} \text {Forward } \\
\text { Barrier }(\mathrm{eV})\end{array}$ & $\begin{array}{c}\mathrm{Ag}^{+} \text {Reverse } \\
\text { Barrier }(\mathrm{eV})\end{array}$ \\
\hline 5 & 3.11 & 2.36 & 2.54 & 2.08 \\
\hline 6 & 1.67 & 1.25 & 1.56 & 1.45 \\
\hline 7 & 2.13 & 1.20 & 0.99 & 0.03 \\
\hline 8 & 1.39 & 0.87 & 0.26 & 0.10 \\
\hline
\end{tabular}

Table 1. Table showing the forward and reverse diffusion barriers of $\mathrm{Ag}^{0}$ and $\mathrm{Ag}^{+}$through rings of different sizes calculated from DFT CI-NEB calculations.

CI-NEB results show that $\mathrm{Ag}^{+}$is the mobile species in a-SiO with the diffusion barriers of $\mathrm{Ag}^{+}$lower than $\mathrm{Ag}^{0}$ for a given ring size. For both Ag species the diffusion barrier decreases with increasing ring size, where the radius of the ring is the controlling feature. The saddle point, corresponding to the highest energy point in the migration path for each calculation occurred where the Ag species is passing though the ring. In the case of small rings, the radius of the ring increases as $\mathrm{Ag}$ is passing through. This effect is exaggerated in 4-member rings where the breaking of a Si-O bond occurs to accommodate the $\mathrm{Ag}^{0}$ or $\mathrm{Ag}^{+}$. This is consistent with the above calculations which suggest that $\mathrm{Ag}$ favours voids and less dense areas. The reduced barrier for $\mathrm{Ag}^{+}$ compared to $\mathrm{Ag}^{0}$ can be explained by the low affinity of $\mathrm{Ag}^{+}$for lattice $\mathrm{O}$. Previous results show that $\mathrm{Ag}^{+}$maintains nearest neighbour distance of $2.2-2.6 \AA$ compared to $\mathrm{Ag}^{0}$ void defect which maintains distances between 2.9 - $3.3 \AA$. Consequently, $\mathrm{Ag}^{+}$ requires less lattice distortion due to its lower effective radius. With devices operating under bias, the barriers for diffusion are reduced for $\mathrm{Ag}^{+}$in the direction of the electric field. Further calculations are required to study the diffusion of $\mathrm{Ag}^{0}$ and $\mathrm{Ag}^{+}$ through grain boundaries, though this represents a formidable modelling challenge and as such is beyond the scope of this work.

\section{Interaction of Ag with oxygen vacancies}

Once $\mathrm{Ag}^{+}$ions have migrated into $\mathrm{a}-\mathrm{SiO}_{2}$, the reduction of $\mathrm{Ag}^{+}$ is required before clustering can occur, the interaction of $\mathrm{Ag}$ with $\mathrm{O}$ vacancies presenting a viable option. Calculations for the $\mathrm{O}$ vacancy give mean, minimum and maximum $V_{O}$ formation energies of 5.3, 4.2 and $6.3 \mathrm{eV}$ respectively. The concentration of oxygen vacancies has a strong dependence upon growth method, with sputter deposited / thermal films known to be vacancy rich [26], [27]. From Fig. 4 we see that the neutral vacancy is favoured at the Fermi energy of $\mathrm{Ag}, \mathrm{W}$ and $\mathrm{Pt}$ with single electron trapping become favourable at $\mathrm{E}_{\mathrm{F}}>6 \mathrm{eV}$. The $\mathrm{Si}-\mathrm{Si}$ bond length and the $(0 /-1)$ transition are negatively correlated, suggesting that vacancies with long $\mathrm{Si}-\mathrm{Si}$ bond lengths energetically favour the trapping of electrons.

With the neutral $\mathrm{O}$ vacancy $\left(\mathrm{V}_{\mathrm{O}}{ }^{0}\right)$ favoured at the $\mathrm{Ag}, \mathrm{W}$ and $\mathrm{Pt}$ Fermi energy, the interaction of $\mathrm{Ag}^{+}$and $\mathrm{V}_{O}{ }^{0}$ was studied. This was achieved by inserting Ag centrally between the two Si atoms involved in the vacancy and relaxing the geometry in the $\mathrm{q}=+1$ charge state. In each of the 144 vacancies, Ag relaxes into a void area of the a- $\mathrm{SiO}_{2}$ lattice near to the vacancy. Of the 144 sites sampled, 117 resulted in a $\left[\mathrm{Ag} / \mathrm{V}_{\mathrm{O}}\right]^{+}$complex (Fig. 5b, 5c), where charge is donated from the two $\mathrm{Si}$ atoms to $\mathrm{Ag}^{+}$. Mulliken charge analysis of the defects show near total reduction of $\mathrm{Ag}^{+}$in the
$[\mathrm{Ag} / \mathrm{Vo}]^{+}$complex with a mean charge of $0.15|e|$ compared to 0.77 $|e|$ at the 27 sites where a $\mathrm{Ag}^{+}$interstitial formed. Further reduction of $\mathrm{Ag}^{+}$occurs by the donation of charge from neighbouring $\mathrm{O}$ in the lattice (Fix. 7c) giving the $\mathrm{Ag}^{+}$charge in a $[\mathrm{Ag} / \mathrm{Vo}]^{+}$complex of as low as $-0.09|e|$.
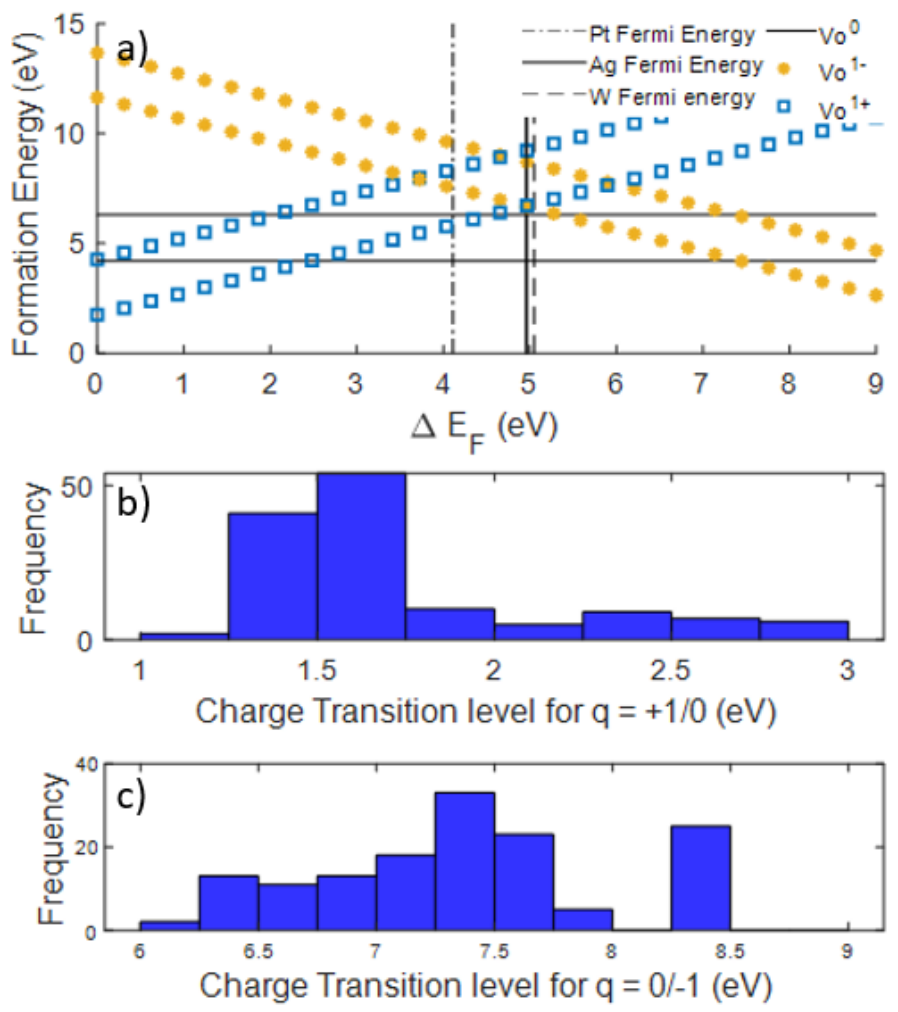

Fig. 4 a) Formation energies of $144 \mathrm{O}$ vacancies as a function of Fermi energy, $\Delta \mathrm{EF}$, where $\Delta \mathrm{F}=0$ at the $\mathrm{VBM}$. The lines represent maxima and minima in the data distribution. $\mathrm{b})$ a histogram showing the $(+1 / 0)$ charge transition position $\mathrm{c})$ a histogram showing the $(0 /-1)$ charge transition position.

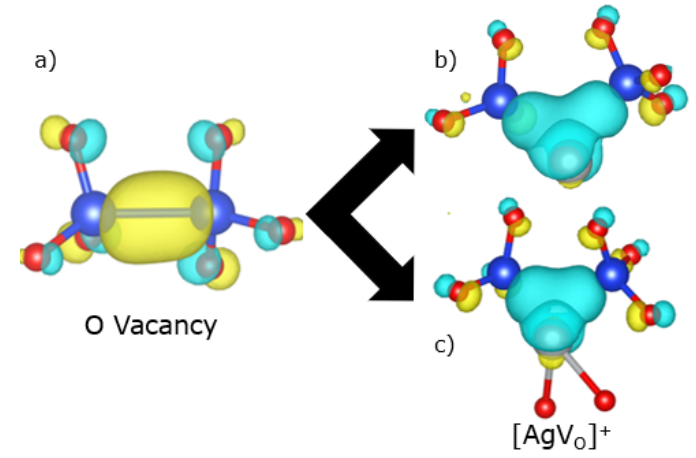

Fig. 5 Schematic showing the HOMO state of the $\mathrm{V}_{\mathrm{O}}$ and $\left[\mathrm{Ag} / \mathrm{V}_{\mathrm{o}}\right]^{+}$defect. The silver, blue and red spheres correspond to $\mathrm{Ag}, \mathrm{Si}$ and $\mathrm{O}$ atoms respectively. The positive and negative charge density is shown as blue and yellow iso-surfaces respectively at a value of \pm 0.07 . a) Typical $V_{O}$, with the HOMO state residing on the two Si atoms involved in the vacancy. b) typical $\left[\mathrm{Ag} / \mathrm{V}_{\mathrm{o}}\right]^{+}$defect and c) $\left[\mathrm{Ag} / \mathrm{V}_{\mathrm{o}}\right]^{+}$defect with nearby oxygens. In both configurations of $\left[\mathrm{Ag} / \mathrm{V}_{\mathrm{o}}\right]^{+}$charge density is donated from $\mathrm{Si}$ to $\mathrm{Ag}$.

A strong correlation was found between the Si-Si bond length and the propensity for the vacancy to trap $\mathrm{Ag}^{+}$. Of the 74 vacancies with a Si-Si bond length below $2.46 \AA$, 27 sites not form a $[\mathrm{Ag} / \mathrm{Vo}]^{+}$complex involved compared to all 70 sites with a $\mathrm{Si}-\mathrm{Si}$ 
bond length $>2.46 \AA$ forming a $[\mathrm{Ag} / \mathrm{Vo}]^{+}$complex. For the 117 $[\mathrm{Ag} / \mathrm{Vo}]^{+}$complexes, a binding energy was calculated for $\mathrm{Ag}^{+}$to the vacancy using two methods. The first involved placing $\mathrm{Ag}^{+}$in the lowest energy interstitial site of the cell where it is not interacting with the vacancy and relaxing the geometry. As the binding energy in this instance is a comparison of $\mathrm{Ag}^{+}$in the lowest energy interstitial site to the $\left[\mathrm{Ag} / \mathrm{V}_{\mathrm{O}}\right]^{+}$complex, a positive binding energy would suggest that the $\left[\mathrm{Ag} / \mathrm{V}_{\mathrm{O}}\right]^{+}$complex is the lowest energy configuration available in the cell. The second method involved placing $\mathrm{Ag}^{+}$in a void $5 \AA$ from the vacancy and relaxing the geometry. In this case, a positive binding energy suggests that an $\mathrm{Ag}^{+}$ion in proximity to a vacancy will have a direct thermodynamic driver to bind to the vacancy. A positive binding energy was found for 22 and $38 \%$, respectively for the two methods. The lower percentage of positive binding energy sites for the lowest interstitial site method is expected as the void interstitial site in all cases had a higher or equal binding energy.

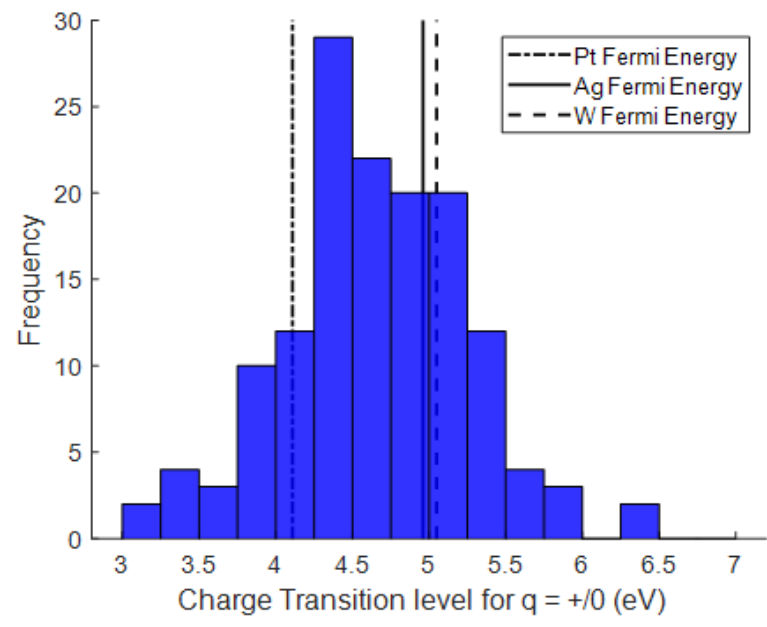

Fig. 6 Histogram showing the $(+1 / 0)$ transition of the $\left[\mathrm{Ag} / \mathrm{V}_{\mathrm{O}}\right]$ complex

Fig. 6 shows the $(+1 / 0)$ transition of the $\left[\mathrm{Ag} / \mathrm{V}_{\mathrm{O}}\right]$ complex. As a result of the higher Fermi energy positions of $\mathrm{Ag}$ and $\mathrm{W}$, considerably more $\left[\mathrm{Ag} / \mathrm{V}_{\mathrm{O}}\right]^{+}$complexes are favoured to trap electrons at the $\mathrm{Ag}(69 \%)$ and $\mathrm{W}(77 \%)$ electrodes compared to Pt (17\%). For a vacancy to be an $\mathrm{Ag}$ reduction site, the site must meet two criteria; Ag must first have a positive binding energy to the vacancy and second the $\left[\mathrm{Ag} / \mathrm{V}_{\mathrm{O}}\right]^{+}$site must be favoured to trap an electron relative to the Fermi energy of the proximate electrodes.

\begin{tabular}{|c|c|c|c|}
\hline & Ring sampling & \multicolumn{2}{|c|}{ Complete sampling } \\
\hline & Interstitial site & Interstitial site & $5 \AA$ away \\
\hline Non-interacting & $27 \%$ & \multicolumn{2}{|c|}{$19 \%$} \\
\hline Positive binding energy & $27 \%$ & $22 \%$ & $38 \%$ \\
\hline Reduction sites at Ag & $27 \%$ & $20 \%$ & $33 \%$ \\
\hline Reduction sites at $\mathrm{W}$ & $27 \%$ & $21 \%$ & $33 \%$ \\
\hline Reduction sites at $\mathrm{Pt}$ & $10 \%$ & $10 \%$ & $11 \%$ \\
\hline
\end{tabular}

Table 2. Table comparing the ring sampling method to the complete sampling method for vacancies as a $\mathrm{Ag}^{+}$reduction site.
For a vacancy to act as a reduction site, it must first trap $\mathrm{Ag}^{+}$. In this case, the barrier for $\mathrm{Ag}^{+}$to bind to the vacancy must be thermodynamically accessible, with the barrier for $\mathrm{Ag}^{+}$to leave the $\left[\mathrm{Ag} / \mathrm{Vo}_{\mathrm{O}}\right]^{+}$complex must be high, thus preventing Ag moving on to the next site. To test this, five CI-NEB calculations were run to determine the forward and reverse barriers for $\left[\mathrm{Ag} / \mathrm{V}_{\mathrm{O}}\right]^{+}$ formation. Five vacancy sites were selected, which are favoured to trap an electron at the Pt Fermi energy giving forward barriers of $0.16,0.60,0.39,0.42$ and $0.25 \mathrm{eV}$, and reverse barriers of 1.22 , $1.53,1.15,1.76$ and $1.40 \mathrm{eV}$, respectively. As such, these sites will act as $\mathrm{Ag}^{+}$traps, with relatively low barriers for $\mathrm{Ag}^{+}$to bind to the vacancy and barriers over $1 \mathrm{eV}$ must be overcome for $\mathrm{Ag}^{+}$to escape the vacancy. Once an $\mathrm{Ag}^{+}$binds to a vacancy forming a $\left[\mathrm{Ag} / \mathrm{V}_{\mathrm{O}}\right]^{+}$complex (Fig. $7 \mathrm{~b}$ ), the complex traps an electron to form a neutral $\left[\mathrm{Ag} / \mathrm{V}_{\mathrm{O}}\right]^{0}$ complex (Fig. 7c). A second $\mathrm{Ag}^{+}$ion then approaches the $\left[\mathrm{Ag} / \mathrm{V}_{\mathrm{O}}\right]^{0}$ complex giving $\left[\mathrm{Ag}_{2} / \mathrm{V}_{\mathrm{O}}\right]^{+}$(Fig. $7 \mathrm{~d}$ ). $\left[\mathrm{Ag}_{2} / \mathrm{V}_{\mathrm{O}}\right]^{+}$then traps an electron to form $\left[\mathrm{Ag}_{2} / \mathrm{V}_{\mathrm{O}}\right]^{0}$ (Fig. $7 \mathrm{e}$ ).

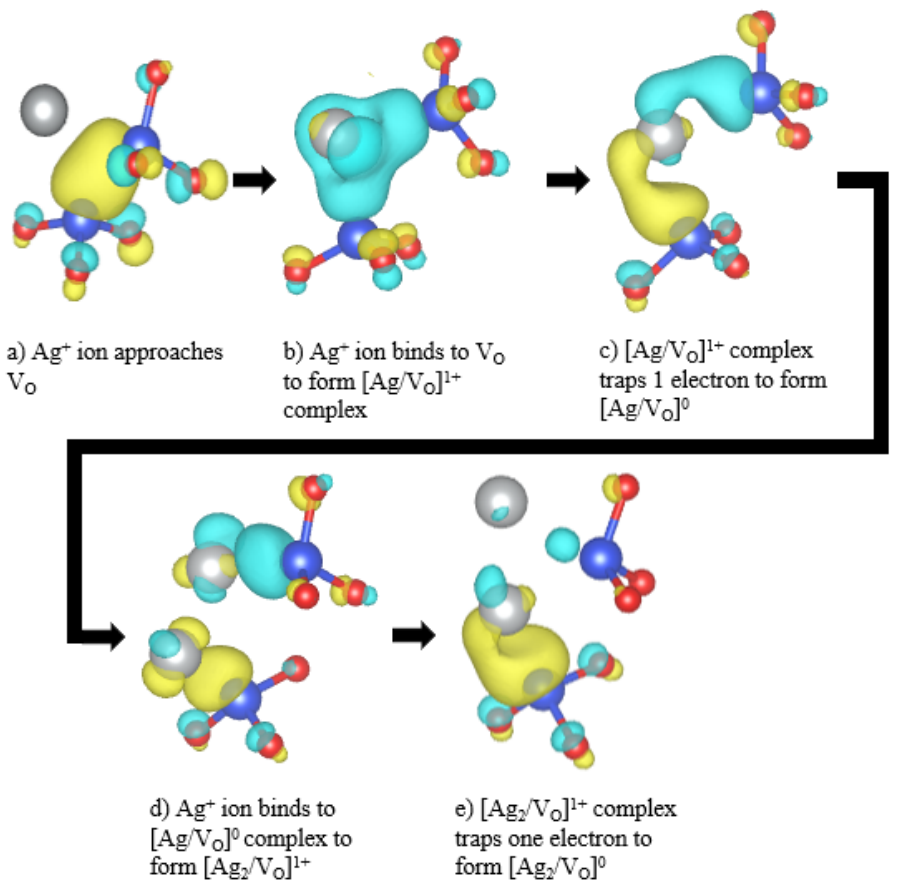

Fig. 7 Schematic showing the $\mathrm{V}_{\mathrm{O}}$ as a $\mathrm{Ag}^{+}$reduction site and subsequent cluster nucleation site. The silver, blue and red spheres correspond to $\mathrm{Ag}, \mathrm{Si}$ and $\mathrm{O}$ atoms respectively. The positive and negative charge density is shown as blue and yellow iso-surfaces respectively at a value of \pm 0.07 .

An interesting aspect observed in the in situ study of the Ag/a$\mathrm{SiO}_{2} / \mathrm{Pt}$ device is the shape of the filament during forming [10]. The thinnest part of the filament was found to be at the inert electrode and the thickest part at the $\mathrm{Ag}$ electrode. This observation can be used as an indication of the redox rates at either electrode, where a low redox rate regime occurs at the Pt electrode, but a higher redox rate regime occurs at the active electrode. This was suggested to be due to thermal heating, however, this could also be explained by considering the $\left[\mathrm{Ag} / \mathrm{V}_{\mathrm{O}}\right]$ complex and its charge states with $33 \%$ of vacancies being reduction and nucleation sites at the Ag electrode and $11 \%$ at the Pt electrode. This correlates well to the multiple cluster mechanism observed 
with the $\mathrm{Ag} / \mathrm{a}-\mathrm{SiO}_{2} / \mathrm{W}$ device compared to the single filament mechanism in the $\mathrm{Ag} / \mathrm{a}-\mathrm{SiO}_{2} / \mathrm{Pt}$ device. In this case, due to the lower mobility of $\mathrm{Ag}$ in the $\mathrm{W}$ device more $\mathrm{Ag}$ ions are present at the Ag electrode. In this case, $33 \%$ of the vacancies they encounter will form a reduction and cluster nucleation site.

\section{Growth of $\mathbf{A g}_{\mathrm{i}}$ clusters}

\begin{tabular}{|c|c|c|c|c|c|}
\hline \multirow[b]{2}{*}{ CI-NEB Results } & \multicolumn{5}{|c|}{ Energy at Coordinate Number (eV) } \\
\hline & 1 & 2 & 3 & 4 & 5 \\
\hline $\begin{array}{c}\text { S1. }\left[\mathrm{AgV}_{\mathrm{O}}\right]+\mathrm{Ag}^{+} \rightarrow \\
{\left[\mathrm{Ag}_{2} \mathrm{~V}_{\mathrm{O}}\right]^{+}} \\
\end{array}$ & 0 & 0.29 & -0.19 & -0.43 & -0.75 \\
\hline $\begin{array}{c}\text { S2. }\left[\mathrm{AgV}_{\mathrm{O}}\right]+\mathrm{Ag}^{+} \rightarrow \\
{\left[\mathrm{Ag}_{2} \mathrm{~V}_{\mathrm{O}}\right]^{+}}\end{array}$ & 0 & 0.01 & 0.22 & -0.20 & -0.46 \\
\hline $\begin{array}{c}\text { S3. }\left[\mathrm{AgV}_{\mathrm{O}}\right]+\mathrm{Ag}^{+} \rightarrow \\
{\left[\mathrm{Ag}_{2} \mathrm{~V}_{\mathrm{O}}\right]^{+}}\end{array}$ & 0 & 0.03 & -0.29 & -0.34 & -0.32 \\
\hline $\begin{array}{c}\text { S4. }\left[\mathrm{AgVo}_{\mathrm{O}}+\mathrm{Ag}^{+} \rightarrow\right. \\
{\left[\mathrm{Ag}_{2} \mathrm{~V}_{\mathrm{O}}\right]^{+}}\end{array}$ & 0 & 0.10 & -0.50 & -0.50 & -0.77 \\
\hline $\begin{array}{c}\text { S5. }\left[\mathrm{AgV}_{\mathrm{O}}\right]+\mathrm{Ag}^{+} \rightarrow \\
{\left[\mathrm{Ag}_{2} \mathrm{~V}_{\mathrm{O}}\right]^{+}}\end{array}$ & 0 & 0.17 & -0.82 & -0.52 & -1.05 \\
\hline \multicolumn{6}{|c|}{ Site 1 cluster building } \\
\hline $\begin{array}{r}{\left[\mathrm{Ag}_{2} \mathrm{~V}_{\mathrm{O}}\right]^{+}+\mathrm{e}^{-}} \\
{\left[\mathrm{Ag}_{2} \mathrm{~V}_{\mathrm{O}}\right]^{0}}\end{array}$ & \multicolumn{5}{|c|}{ Electron trap at $3.60 \mathrm{eV}$. Relaxation of $=1.08 \mathrm{eV}$} \\
\hline $\begin{array}{c}{\left[\mathrm{Ag}_{2} \mathrm{~V}_{\mathrm{O}}\right]^{0}+\mathrm{Ag}^{+} \rightarrow} \\
{\left[\mathrm{Ag}_{3} \mathrm{~V}_{\mathrm{O}}\right]^{+}}\end{array}$ & 0 & 0.34 & -0.33 & -0.36 & -0.48 \\
\hline $\begin{array}{c}{\left[\mathrm{Ag}_{3} \mathrm{~V}_{\mathrm{O}}\right]^{+}+\mathrm{Ag}^{+} \rightarrow} \\
{\left[\mathrm{Ag}_{4} \mathrm{~V}_{\mathrm{O}}\right]^{++}} \\
\end{array}$ & 0 & 0.38 & -0.03 & -0.56 & -1.09 \\
\hline $\begin{array}{c}{\left[\mathrm{Ag}_{4} \mathrm{~V}_{\mathrm{O}}\right]^{2+}+2 \mathrm{e}^{-} \rightarrow} \\
{\left[\mathrm{Ag}_{4} \mathrm{~V}_{\mathrm{O}}\right]^{0}}\end{array}$ & \multicolumn{5}{|c|}{ Electron trap at $3.96 \mathrm{eV}$. Relaxation of $=3.24 \mathrm{eV}$} \\
\hline $\begin{array}{c}{\left[\mathrm{Ag}_{4} \mathrm{~V}_{\mathrm{O}}\right]^{0}+\mathrm{Ag}^{+} \rightarrow} \\
{\left[\mathrm{Ag}_{5} \mathrm{~V}_{\mathrm{O}}\right]^{+}}\end{array}$ & 0 & -0.03 & -0.40 & -0.88 & -0.97 \\
\hline
\end{tabular}

Table 3. Table showing the results of CI-NEB calculations for Ag clustering.

To test the propensity for a second $\mathrm{Ag}^{+}$ion to bind to the $\left[\mathrm{Ag} / \mathrm{V}_{\mathrm{O}}\right]$ complex, CI-NEB calculations were run to determine the forward and reverse barriers with results shown in Table. 3. We see that as with the first $\mathrm{Ag}^{+}$ion there is considerable increase in reverse barrier suggesting that the second $\mathrm{Ag}^{+}$will also trap to the complex. In each case, the $\left[\mathrm{Ag}_{2} / \mathrm{V}_{\mathrm{O}}\right]^{+}$is favoured to trap an electron at the $\mathrm{Ag}, \mathrm{W}$ and Pt Fermi energies. Due to the high computational cost associated with CI-NEB calculations, the continued growth of an Ag cluster was carried out on one vacancy site, where the process of adding ions and trapping electrons was continued. From Table. 3 we see that the $\left[\mathrm{Ag}_{2} / \mathrm{V}_{\mathrm{O}}\right]^{+}$complex for this site is favoured to trap an electron at $3.60 \mathrm{eV}$ giving $\left[\mathrm{Ag}_{2} / \mathrm{V}_{\mathrm{O}}\right]^{0}$ at both electrodes, with a structural relaxation of $1.08 \mathrm{eV}$. Adding a third $\mathrm{Ag}^{+}$to the system and running a CI-NEB gives a barrier of $0.34 \mathrm{eV}$ and binding energy of $0.48 \mathrm{eV}$. In this case the $\left[\mathrm{Ag}_{3} / \mathrm{V}_{\mathrm{O}}\right]^{+}$ complex is favoured to trap an electron at a Fermi energy of 4.4 $\mathrm{eV}$. As such, this complex would remain positive at the $\mathrm{Pt}$ electrode, but would trap an electron to form $\left[\mathrm{Ag}_{3} / \mathrm{V}_{\mathrm{O}}\right]^{0}$ at the $\mathrm{Ag}$ electrode. A barrier of $0.38 \mathrm{eV}$ and binding energy of $1.09 \mathrm{eV}$ was calculated for the formation of a $\left[\mathrm{Ag}_{4} / \mathrm{V}_{\mathrm{O}}\right]^{2+}$ complex, which was favoured to trap two electrons at $3.96 \mathrm{eV}$ suggesting the neutral $\left[\mathrm{Ag}_{4} / \mathrm{V}_{\mathrm{O}}\right]^{0}$ complex is favoured at both the Pt and $\mathrm{Ag}$ Fermi energies. The formation of the $\left[\mathrm{Ag}_{5} / \mathrm{V}_{\mathrm{O}}\right]^{+}$complex was found to be a barrier-less process with a binding energy of $0.97 \mathrm{eV}$. From these calculations it is clear that the barriers for $\mathrm{Ag}^{+}$ions to bind with the vacancy complexes are relatively low, with high binding energies. Thus, providing a strong thermodynamic driver for the clustering process.

\section{CONCLUSION}

Two configurations of the $\mathrm{Ag}^{0}$ interstitial were found. In the first, $\mathrm{Ag}^{0}$ occupies a void in the lattice, with the HOMO consisting primarily of Ag s-character. The second involves the widening of an $\mathrm{O}-\mathrm{Si}-\mathrm{O}$ bond angle, and a subsequent charge donation from $\mathrm{Ag}$ to $\mathrm{Si}$. The $\mathrm{Ag}^{+}$interstitial was found to relax into void areas whilst maintaining a nearest neighbour distance of $2.2-2.6 \AA$ to a lattice $O$. The correlation of incorporation energy to the steric crowding around $\mathrm{Ag}$ by the lattice suggests that $\mathrm{Ag}$ will traverse $\mathrm{a}-\mathrm{SiO}_{2}$ via a void crossing mechanism. This is confirmed by CI-NEB calculations which show that the adiabatic barriers for $\mathrm{Ag}^{0}$ and $\mathrm{Ag}^{+}$decrease when migrating through larger rings. Furthermore, the barriers for $\mathrm{Ag}^{+}$were found to be lower than $\mathrm{Ag}^{0}$ for a given ring size.

The $\mathrm{Ag}^{+}$interstitial defect was found to have the lowest defect formation energy at the Fermi energies of $\mathrm{Ag}, \mathrm{W}$ and $\mathrm{Pt}$, though the proximity of the $(+1 / 0)$ transition to the Ag Fermi energy suggests $\mathrm{Ag}^{0}$ will be favoured under bias. The $\mathrm{Ag}^{+}$interstitial is favoured at the Pt Fermi energy, therefore, $\mathrm{Ag}^{+}$ions are not reduced at the Pt electrodes via electron tunnelling. Instead, $\mathrm{Ag}^{+}$ ions are reduced by $\mathrm{O}$ vacancies after forming $\left[\mathrm{Ag} / \mathrm{V}_{\mathrm{O}}\right]^{+}$. $\left[\mathrm{Ag} / \mathrm{V}_{\mathrm{O}}\right]^{+}$ are then able to trap an electron to form an $[\mathrm{Ag} / \mathrm{Vo}]^{0}$. A second $\mathrm{Ag}^{+}$ion can bind to $\left[\mathrm{Ag} / \mathrm{Vo}^{0}{ }^{0}\right.$ to form $\left[\mathrm{Ag}_{2} / \mathrm{Vo}^{+}\right.$, which is again favoured to trap an electron giving an $\mathrm{Ag}_{2}$ dimer bound to a $\mathrm{V}_{\mathrm{O}}$ $\left[\mathrm{Ag}_{2} / \mathrm{Vo}^{0}\right.$. This vacancy mediated $\mathrm{Ag}$ reduction mechanism is more dominant at the $\mathrm{Ag}$ and $\mathrm{W}$ electrodes due to the Fermi energy positions relative to the a-SiO 2 band gap. The process of $\mathrm{Ag}^{+}$ions migrating towards and binding to the $\left[\mathrm{Ag}_{\mathrm{i}} / \mathrm{V}_{\mathrm{O}}\right]$ complex has been shown to be thermodynamically favourable with low diffusion barriers and high binding energies.

The $\mathrm{Vo}_{\mathrm{o}}$ site is a strong candidate for Ag cluster nucleation, with 33,33 and $11 \%$ of vacancies found to trap and reduce $\mathrm{Ag}^{+}$in proximity to the $\mathrm{Ag}, \mathrm{W}$ and $\mathrm{Pt}$ electrodes respectively. The direct probing of this mechanism is difficult as the specific $\mathrm{Ag} / \mathrm{V}_{\mathrm{O}}$ interaction is very small. However, indirect testing can be carried out on $\mathrm{Ag} / \mathrm{a}-\mathrm{SiO}_{2}$ devices to support the data by generating $\mathrm{O}$ vacancies in the oxide. This could be done by applying a negative bias to generate vacancies as in the VCM mechanism or by growing $\mathrm{a}^{-\mathrm{SiO}_{\mathrm{x}}}$ layers with different concentrations of $\mathrm{O}$ vacancies. In situ stressing of the devices would result in a shift from a low redox rate regime to a high redox rate regime as the concentration of $\mathrm{O}$ vacancies increases.

\section{ACKNOWLEDGEMENTS}

The A*STAR Graduate Academy is acknowledged for its graduate scholarship under the ARAP program. We also acknowledge funding provided by EPSRC (EP/L015862/1) and the use of the ARCHER High Performance Computing Facility via membership to the UK's HPC Materials Chemistry Consortium which is funded by EPSRC (EP/L000202). The Leverhulme Trust is also acknowledged for funding part of this work (RPG-2016135) 


\section{REFERENCES}

[1] D. Ielmini, "Resistive switching memories based on metal oxides: mechanisms, reliability and scaling," Semicond. Sci. Technol., vol. 31, no. 6, p. 63002, May 2016.

[2] B. R. Waser, R. Dittmann, G. Staikov, and K. Szot, "Redox-Based Resistive Switching Memories Nanoionic Mechanisms, Prospects , and Challenges," pp. 2632-2663, 2009.

[3] X. Wu et al., "Atomic Scale Modulation of SelfRectifying Resistive Switching by Interfacial Defects," Adv. Sci. (Weinheim, Baden-Wurttemberg, Ger., vol. 5, no. 6, p. 1800096, Apr. 2018.

[4] X. Wu et al., "Intrinsic nanofilamentation in resistive switching," J. Appl. Phys., vol. 113, no. 11, p. 114503, 2013.

[5] N. Raghavan, K. L. Pey, W. Liu, X. Wu, X. Li, and M. Bosman, "Evidence for compliance controlled oxygen vacancy and metal filament based resistive switching mechanisms in RRAM," Microelectron. Eng., vol. 88, no. 7, pp. 1124-1128, 2011.

[6] B. H. P. Wong et al., "Metal - Oxide RRAM," 2012.

[7] U. Celano et al., "Understanding the Dual Nature of the Filament Dissolution in Conductive Bridging Devices," $J$. Phys. Chem. Lett., vol. 6, no. 10, pp. 1919-1924, May 2015.

[8] A. Mehonic et al., "Electrically tailored resistance switching in silicon oxide," Nanotechnology, vol. 23, no. 45, p. 455201, 2012.

[9] Y. Yang et al., "Electrochemical dynamics of nanoscale metallic inclusions in dielectrics.," Nat. Commun., vol. 5, no. May, p. 4232, 2014.

[10] Y. Yang, P. Gao, S. Gaba, T. Chang, X. Pan, and W. Lu, "Observation of conducting filament growth in nanoscale resistive memories," Nat. Commun., vol. 3, p. 732, 2012.

[11] K. Patel, J. Cottom, M. Bosman, A. J. Kenyon, and A. L. Shluger, "Theoretical Study of Ag Interactions in Amorphous Silica RRAM Devices," in 2018 IEEE International Symposium on the Physical and Failure Analysis of Integrated Circuits (IPFA), 2018, pp. 1-5.

[12] A. M. El-Sayed, M. B. Watkins, A. L. Shluger, and V. V. Afanas'Ev, "Identification of intrinsic electron trapping sites in bulk amorphous silica from ab initio calculations," Microelectron. Eng., vol. 109, pp. 68-71, 2013.

[13] B. G. LIPPERT, J. HUTTER, and M. PARRINELLO, “A hybrid Gaussian and plane wave density functional scheme," Mol. Phys., vol. 92, no. 3, pp. 477-488, 1997.

[14] J. Vandevondele, M. Krack, F. Mohamed, M. Parrinello, T. Chassaing, and J. Hutter, "Quickstep: Fast and accurate density functional calculations using a mixed Gaussian and plane waves approach," Comput. Phys. Commun., vol. 167, no. 2, pp. 103-128, 2005.

[15] J. Hutter, M. Iannuzzi, F. Schiffmann, and J. VandeVondele, "cp2k: atomistic simulations of condensed matter systems," Wiley Interdiscip. Rev. Comput. Mol. Sci., vol. 4, no. 1, pp. 15-25, 2014.

[16] J. VandeVondele and J. Hutter, "Gaussian basis sets for accurate calculations on molecular systems in gas and condensed phases," J. Chem. Phys., vol. 127, no. 11, p. $114105,2007$.

[17] S. Goedecker, M. Teter, and J. Hutter, "Separable dualspace Gaussian pseudopotentials," Phys. Rev. B, vol. 54, no. 3, pp. 1703-1710, Jul. 1996.

[18] M. Guidon, J. Hutter, and J. VandeVondele, "Auxiliary Density Matrix Methods for Hartree-Fock Exchange Calculations," J. Chem. Theory Comput., vol. 6, no. 8, pp. 2348-2364, 2010.

[19] W. Martienssen and H. Warlimont, Springer Handbook of Condensed Matter and Materials Data. 2005.

[20] S. B. Zhang and J. E. Northrup, "Chemical potential dependence of defect formation energies in GaAs: Application to Ga self-diffusion," Phys. Rev. Lett., vol. 67, no. 17, pp. 2339-2342, Oct. 1991.

[21] S. Lany and A. Zunger, "Accurate prediction of defect properties in density functional supercell calculations," Model. Simul. Mater. Sci. Eng., vol. 17, no. 8, p. 84002, 2009.

[22] D. E. Eastman, "Photoelectric Work Functions of Transition, Rare-Earth, and Noble Metals," Phys. Rev. B, vol. 2, no. 1, pp. 1-2, Jul. 1970.

[23] A. Ohta et al., "Evaluation of valence band top and electron affinity of $\mathrm{SiO} 2$ and Si-based semiconductors using X-ray photoelectron spectroscopy Evaluation of valence band top and electron af fi nity of $\mathrm{SiO} 2$ and $\mathrm{Si}$ based," no. 0001, pp. 4-9.

[24] Y.-C. Yeo, P. Ranade, T.-J. King, and C. Hu, "Effects of high- $\kappa$ gate dielectric materials on metal and silicon gate workfunctions," IEEE Electron Device Lett., vol. 23, no. 6, pp. 342-344, 2002.

D. Z. Gao, A.-M. El-Sayed, and A. L. Shluger, "A mechanism for Frenkel defect creation in amorphous $\mathrm{SiO}$ 2 facilitated by electron injection," Nanotechnology, vol. 27, no. 50, p. 505207, 2016.

[26] W. L. Warren, M. R. Shaneyfelt, D. M. Fleetwood, J. R. Schwank, P. S. Winokur, and R. A. B. Devine, "Microscopic nature of border traps in MOS oxides," IEEE Trans. Nucl. Sci., vol. 41, no. 6, pp. 1817-1827, 1994. 
[27] J. Santamaría, E. Iborra, F. S. Quesada, G. G. Díaz, and M. R. Vidal, "Sputtering of $\mathrm{SiO} 2$ in O2-Ar atmospheres," Thin Solid Films, vol. 139, no. 2, pp. 201-208, 1986. 